\title{
Peramalan Banyak Pengunjung Pantai Pandasimo Bantul Menggunakan Regresi Runtun Waktu dan Seasonal Autoregressive Integrated Moving Average Exogenous
}

\author{
Tito Tatag Prakoso ${ }^{1}$, Etik Zukhronah ${ }^{2}$, Hasih Pratiwi ${ }^{3}$ \\ Program Studi Statistika, Fakultas Matematika dan Ilmu Pengetahuan Alam \\ Universitas Sebelas Maret \\ titotatag@gmail.com, etikzukhronah@staff.uns.ac.id, hasihpratiwi@staff.uns.ac.id
}

\begin{abstract}
Forecasting is a ways to predict what will happen in the future based on the data in the past. Data on the number of visitors in Pandansimo beach are time series data. The pattern of the number of visitors in Pandansimo beach is influenced by holidays, so it looks like having a seasonal pattern. The majority of Indonesian citizens are Muslim who celebrate Eid Al-Fitr in every year. The determination of Eid Al-Fitr does not follow the Gregorian calendar, but based on the Lunar calendar. The variation of the calendar is about the determination of Eid Al-Fitr which usually changed in the Gregorian calendar, because in the Gregorian calendar, Eid Al-Fitr day will advance one month in every three years. Data that contain seasonal and calendar variations can be analyzed using time series regression and Seasonal Autoregressive Integrated Moving Average Exogenous (SARIMAX) models. The aims of this study are to obtain a better model between time series regression and SARIMAX and to forecast the number of Pandansimo beach visitors using a better model. The result of this study indicates that the time series regression model is a better model. The forecasting from January to December 2018 in succession are $13255,6674,8643,7639,13255,8713,22635,13255,13255,9590,8549,13255$ visitors.
\end{abstract}

Keywords: time series regression, seasonal, calendar variations, SARIMAX, forecasting

\section{Pendahuluan}

Pantai Pandansimo berada di Desa Poncosari, Srandakan, Kabupaten Bantul, Provinsi Daerah Istimewa Yogyakarta. Minat masyarakat untuk berwisata di pantai Pandansimo berpengaruh pada sektor perekonomian Kabupaten Bantul, khususnya akan berdampak bagi warga yang tinggal di sekitar pantai. Peningkatan pengunjung pantai memberikan dampak positif dengan meningkatnya perekonomian daerah dan juga perekonomian warga sekitar, begitu pula sebaliknya. Pengunjung suatu tempat wisata dapat dipengaruhi oleh hari libur. Di hari libur, termasuk pada libur hari raya Idul Fitri, pengunjung biasanya lebih banyak daripada hari biasa. Data pengunjung obyek wisata dari waktu ke waktu merupakan data runtun waktu. Data runtun waktu adalah suatu himpunan pengamatan yang dibangun secara berurutan dalam waktu yang konsisten. Peramalan jumlah pengunjung obyek wisata dapat dimanfaatkan untuk memperkirakan banyaknya pemasukan di sektor ekonomi. Menurut Hanke dan Wichern [1] pola musiman terjadi jika suatu data dipengaruhi oleh faktor musiman. Pola data musiman mempunyai 
pola berulang dari periode ke periode berikutnya. Perbedaan penggunaan kalender Masehi dengan Hijriyah pada suatu data runtun waktu menyebabkan adanya variasi kalender.Memodelkan pola data yang mempunyai variasi kalender dan mengandung unsur musiman dapat digunakan analisis runtun waktu dengan pendekatan Seasonal Autoregressive Integrated Moving Average Exogenous (SARIMAX). Lee et al. [2] melakukan penelitian tentang model regresi runtun waktu dengan efek variasi kalender bulan Ramadhan. Dalam penelitian tersebut digunakan data penjualan baju muslim anak laki-laki dengan variabel dummy yaitu variabel musiman bulanan dan variabel dummy untuk efek variasi kalender. Cosasi [3] melakukan penelitian terhadap wisatawan Grojogan Sewu menggunakan regresi runtun waktu dengan variasi kalender. Sofyana dkk. [4] meramalkan banyak penumpang kereta api Fajar Utama jurusan YogyakartaPasar Senen menggunakan ARIMAX dengan variasi kalender. Arunraj et al. [5] melakukan penelitian tentang penjualan harian di industri retail makanan menggunakan model SARIMAX.

Banyaknya pengunjung pantai Pandansimo pada saat liburan setelah hari raya Idul Fitri menunjukkan kenaikan yang signifikan dibandingkan dengan hari lainnya. Hal tersebut menunjukkan bahwa data pengunjung pantai Pandansimo mengandung variasi kalender. Berdasarkan hal tersebut, maka pada paper ini dilakukan peramalan banyak pengunjung pantai Pandansimo menggunakan model regresi runtun waktu dan SARIMAX.

\section{Metode Penelitian}

Data yang digunakan adalah data sekunder dari Statistik Pariwisata DIY [6] dengan data in-sample sebanyak 60 observasi dari bulan Januari 2012 hingga Desember 2016 dan data out-sample sebanyak 12 observasi dari bulan Januari 2017 hingga Desember 2017. Langkah-langkah yang dilakukan dalam penelitian ini adalah

1. Mengidentifikasi kestasioneran data menggunakan plot data dan plot ACF serta uji $\mathrm{ADF}$.

2. Menentukan variabel dummy untuk efek variasi kalender hari Raya Idul Fitri dan musiman 12 bulan. Variabel dummy untuk variasi kalender yaitu bulan yang terdapat hari raya Idul Fitri adalah $V_{t}$, yang bernilai 1 untuk bulan yang terdapat hari raya sedangkan untuk bulan lainnya bernilai 0 . Selanjutnya $V_{t+1}$ bernilai 1 untuk bulan setelah Hari Raya Idul Fitri dan $V_{t+1}$ bernilai 0 untuk bulan lainnya. Variabel dummy untuk musiman adalah $S_{2, t}$ yang bernilai 1 untuk bulan Februari dan 0 untuk bulan 
lainnya, $S_{3, t}$ yang bernilai 1 untuk bulan Maret dan 0 bulan lainnya, dan seterusnya hingga $S_{12, t}$.

3. Melakukan pemodelan regresi runtun waktu dengan variabel dummy. Estimasi parameter model regresi runtun waktu variabel dummy dilakukan dengan metode Ordinary Least Square (OLS) dan uji signifikasi parameter dengan menggunakan uji t. Jika terdapat parameter variabel dummy yang tidak signifikan maka dilakukan estimasi ulang dengan tidak melibatkan parameter yang tidak signifikan tersebut sehingga akan diperoleh model regresi runtun waktu dengan semua parameter yang telah signifikan.

4. Melakukan uji asumsi white noise dengan uji Ljung-Box dan uji normalitas menggunakan uji Kolmogorov-Smirnov.

5. Melakukan pemodelan SARIMA dengan melihat plot ACF dan PACF pada data yang telah stasioner.

6. Melakukan pemodelan SARIMAX dengan variabel dummy yang diperoleh dari langkah 2, kemudian melakukan uji seperti langkah 4.

7. Membandingkan RMSE in-sample dan out-sample dari model yang residunya telah memenuhi asumsi white noise dan berdistribusi normal. Model terbaik adalah model yang mempunyai nilai RMSE out-sample terkecil.

8. Melakukan peramalan pengunjung obyek wisata pantai Pandansimo menggunakan model terbaik.

\section{Hasil dan Pembahasan}

Penelitian ini menggunakan data bulanan banyaknya pengunjung Pantai Pandansimo Bantul Yogyakarta dari bulan Januari 2012 sampai dengan bulan Desember 2016 yang berjumlah 60 observasi sebagai data in-sample, dan bulan Januari hingga Desember 2017 sebagai data out-sample. Plot data runtun waktu banyak pengunjung Pantai Pandansimo dari tahun 2012 sampai 2016 disajikan pada Gambar 1.

Pada Gambar 1, sumbu X menyatakan periode waktu, yaitu dalam bulan dan tahun sedangkan sumbu y menyatakan banyak pengunjung Pantai Pandansimo. Gambar 1 menunjukkan bahwa terdapat peningkatan banyak pengunjung secara signifikan pada bulan-bulan tertentu dibandingkan dengan bulan lain setiap tahunnya. Pada bulan Agustus tahun 2012, 2013 dan 2014, banyak pengunjung meningkat secara signifikan dibandingkan bulan-bulan lainnya. Kemudian pada tahun 2015, 2016 bulan Juli juga mengalami peningkatan yang signifikan. 


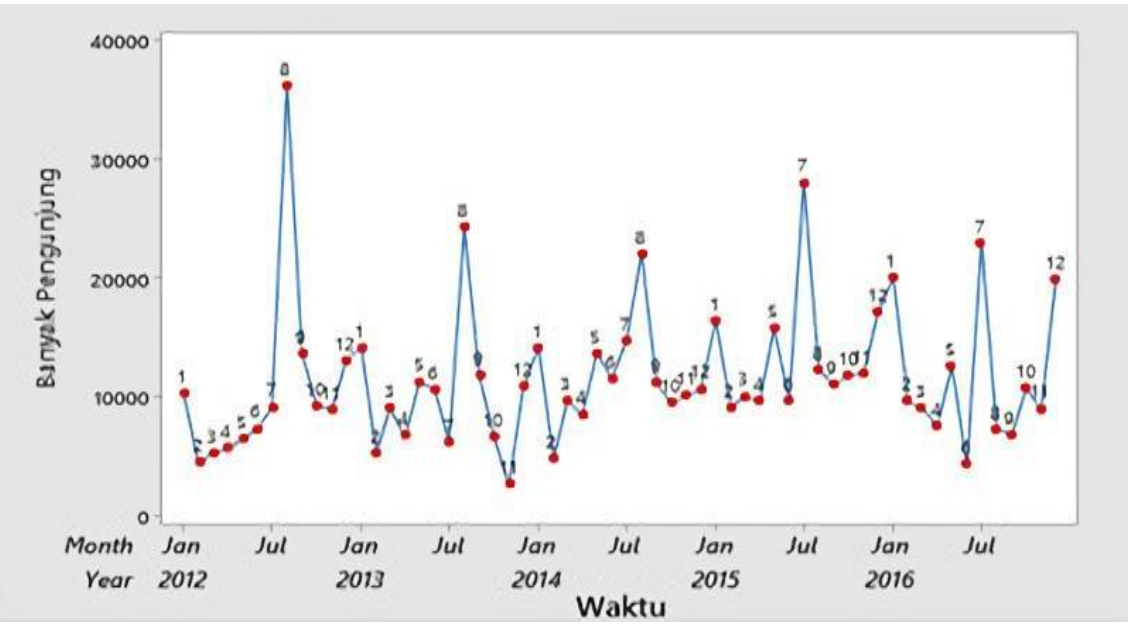

Gambar 1. Plot Banyak Pengunjung Pantai Pandansimo

\subsection{Pemodelan Regresi Runtun Waktu}

Hasil regresi runtun waktu antara pengunjung pantai Pandasimo dan waktu $(t)$, variabel dummy efek variasi kalender $\left(V_{t}, V_{t+1}\right)$ dan musiman $\left(S_{2}, S_{3}, \ldots, S_{12}\right)$ terdapat pada Tabel 1.

Tabel 1. Estimasi Parameter Regresi Runtun Waktu dengan Variabel Dummy Tren, Efek Variasi Kalender, dan Musiman.

\begin{tabular}{|c|c|c|c|c|c|c|c|}
\hline $\begin{array}{l}\text { Para- } \\
\text { meter }\end{array}$ & $\begin{array}{l}\text { Esti- } \\
\text { masi }\end{array}$ & Nilai- $p$ & Ket & $\begin{array}{l}\text { Para- } \\
\text { meter }\end{array}$ & $\begin{array}{l}\text { Esti- } \\
\text { masi }\end{array}$ & Nilai- $p$ & Ket \\
\hline$\beta_{0}$ & 139212,6 & $<2,2 \times 10^{-16}$ & Signifikan & $\beta_{6}$ & $-6539,44$ & 0,00090 & Signifikan \\
\hline$t$ & 44,36 & 0,06081 & Tidak & $\beta_{7}$ & $-8645,57$ & 0,00034 & Signifikan \\
\hline$V_{t}$ & 15986,9 & $5,39 \times 10^{-12}$ & Signifikan & $\beta_{8}$ & $-2099,89$ & 0,45739 & Tidak \\
\hline$V_{t+1}$ & 1345,89 & 0,56161 & Tidak & $\beta_{9}$ & $-5030,70$ & 0,05352 & Tidak \\
\hline$\beta_{2}$ & $-8400,97$ & $1,95910^{-5}$ & Signifikan & $\beta_{10}$ & $-5840,11$ & 0,00317 & Signifikan \\
\hline$\beta_{3}$ & $-6476,94$ & 0,00099 & Signifikan & $\beta_{11}$ & $-6925,68$ & 0,00047 & Signifikan \\
\hline$\beta_{4}$ & $-7524,70$ & 0,00013 & Signifikan & $\beta_{12}$ & $-1185,45$ & 0,55030 & Tidak \\
\hline$\beta_{5}$ & $-3242,67$ & 0,99720 & Tidak & & & & \\
\hline
\end{tabular}

Tabel 1 menunjukkan bahwa parameter tren, dan $V_{t+1}, \beta_{5}, \beta_{8}, \beta_{9}, \beta_{12}$ tidak signifikan karena nilai- $p$ lebih dari 0,05 . Berdasarkan hal tersebut, maka model regresi runtun waktu ini tidak sesuai digunakan untuk meramalkan banyak pengunjung pantai Pandansimo. Sehingga dilakukan uji regresi runtun waktu tanpa menggunakan variabel dummy, tren, dan $V_{t+1}, \beta_{5}, \beta_{8}, \beta_{9}, \beta_{12}$. Uji model regresi runtun waktu dengan variabel dummy efek variasi kalender dan musiman terdapat pada Tabel 2. 
Tabel 2. Estimasi Parameter Regresi Runtun Waktu dengan Dummy Efek Variasi

Kalender, dan Musiman.

\begin{tabular}{cccl}
\hline Parameter & Estimasi & Nilai- $p$ & Ket \\
\hline$\beta_{0}$ & 13255,13 & $<2,2 \times 10^{-16}$ & Signifikan \\
$V_{t}$ & 15978,42 & $<2,2 \times 10^{-16}$ & Signifikan \\
$\beta_{2}$ & $-6580,93$ & $7,097 \times 10^{-5}$ & Signifikan \\
$\beta_{3}$ & $-4612,53$ & 0,00535 & Signifikan \\
$\beta_{4}$ & $-5615,93$ & 0,00069 & Signifikan \\
$\beta_{6}$ & $-4541,93$ & 0,00610 & Signifikan \\
$\beta_{7}$ & $-6598,58$ & 0,00063 & Signifikan \\
$\beta_{10}$ & $-3665,13$ & 0,02691 & Signifikan \\
$\beta_{11}$ & $-4706,33$ & 0,00449 & Signifikan \\
\hline
\end{tabular}

Tabel 2 menunjukkan semua parameter signifikan, karena nilai- $p$ setiap parameter kurang dari 0,05. Model regresi yang diperoleh

$Z_{t}=13255+15978 V_{t}-6580 S_{2, t}-4613 S_{3, t}-5616 S_{4, t}-4542 S_{6, t}-6599 S_{7, t}-3665 S_{10, t}-$ $4706 S_{11, t}$

Kemudian dilakukan uji white noise dan normalitas terhadap residu. Hasil uji white noise menunjukkan nilai- $p$ untuk 12 lag pertama sebesar 0,7217 yang berarti tidak terdapat korelasi antar residu. Hasil uji normalitas menggunakan uji KolmogorovSmirnov diperoleh nilai- $p$ sebesar 0,8941 berarti residu berdistribusi normal. Berdasarkan hal tersebut, maka regresi runtun waktu dengan variabel dummy efek variasi kalender, dan musiman sesuai digunakan untuk meramalkan banyak pengunjung pantai Pandansimo.

\subsection{Pemodelan SARIMAX}

Langkah awal untuk analisis ini yaitu menentukan kestasioneran data dengan melihat plot data in-sample dari tahun 2012 hingga 2016 seperti yang terlihat pada Gambar 1. Hasil output uji ADF menunjukkan nilai- $p$ sebesar 0,01 kurang dari $\alpha=0.05$ yang berarti data stasioner. Plot ACF dan PACF dari data banyak pengunjung pantai Pandansimo disajikan pada Gambar 2 dan Gambar 3. Gambar 2 menunjukkan bahwa ada unsur musiman dalam data karena pada lag 12 bernilai tinggi. Plot ACF dan PACF ini digunakan untuk menentukan orde AR dan MA. 


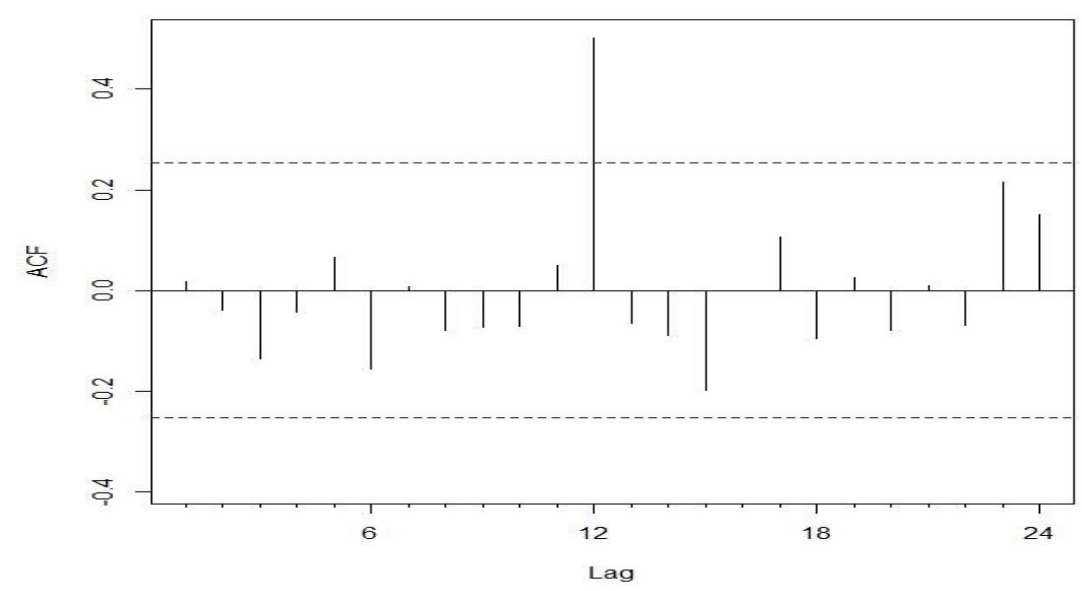

Gambar 2. Plot ACF Banyak Pengunjung Pantai Pandansimo

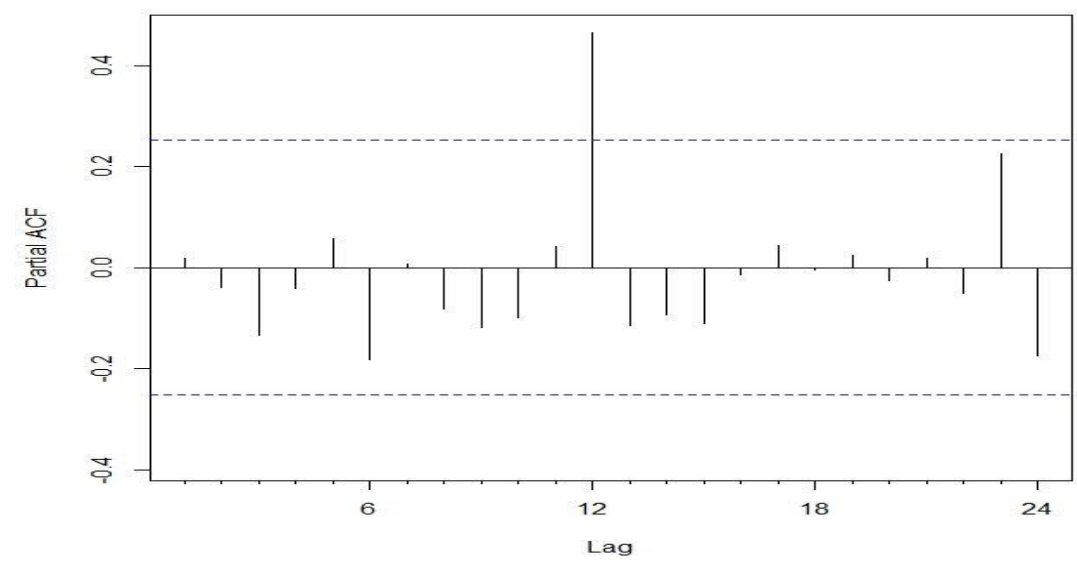

Gambar 3. Plot PACF Banyak Pengunjung Pantai Padansimo

Gambar 2 dan Gambar 3 menunjukkan bahwa pada lag awal tidak ada yang keluar dari pita konfidensi, sehingga orde $p$ dan $q$ sama dengan 0 , namun pada pola musiman periode 12 keluar dari pita konfidensi, sehingga orde $\mathrm{P}=1$ dan $\mathrm{Q}=1$. Didapatkan kemungkinan model SARIMAX sebagai berikut SARIMAX $(0,0,0)(1,0,1)^{12}$, SARIMAX $(0,0,0)(0,0,1)^{12}$, SARIMAX $(0,0,0)(1,0,0)^{12}$. Berikut adalah hasil estimasi model SARIMAX dengan menambahkan variabel dummy efek variasi kalender, tren, dan musiman.

1) Model SARIMAX $(0,0,0)(1,0,1)^{12}$

Hasil estimasi parameter model SARIMAX $(0,0,0)(1,0,1)^{12}$ disajikan pada Tabel 3. 
Tabel 3. Hasil Estimasi Parameter Model SARIMAX $(0,0,0)(1,0,1)^{12}$

\begin{tabular}{clllclll}
\hline $\begin{array}{c}\text { Para- } \\
\text { meter }\end{array}$ & $\begin{array}{l}\text { Esti- } \\
\text { Masi }\end{array}$ & Nilai- $p$ & Keterangan & $\begin{array}{l}\text { Para- } \\
\text { meter }\end{array}$ & $\begin{array}{l}\text { Esti- } \\
\text { masi }\end{array}$ & Nilai- $p$ & Keterangan \\
\hline$\phi_{1}$ & 0,29490 & 0,01243 & Signifikan & $\beta_{5}$ & $-2095,06$ & 0,01615 & Signifikan \\
$\theta_{1}$ & $-0,99999$ & $1,072 \times 10^{-8}$ & Signifikan & $\beta_{6}$ & $-5274,48$ & $1,75 \times 10^{-9}$ & Signifikan \\
$\beta_{0}$ & 14379,95 & $<2,2 \times 10^{-16}$ & Signifikan & $\beta_{7}$ & $-8224,11$ & $3,17 \times 10^{-13}$ & Signifikan \\
$V_{t}$ & 16267,86 & $<2,2 \times 10^{-16}$ & Signifikan & $\beta_{9}$ & $-3406,26$ & $7,23 \times 10^{-5}$ & Signifikan \\
$\beta_{2}$ & $-7784,55$ & $<2,2 \times 10^{-16}$ & Signifikan & $\beta_{10}$ & $-4836,23$ & $1,53 \times 10^{-8}$ & Signifikan \\
$\beta_{3}$ & $-5547,48$ & $1,304 \times 10^{-10}$ & Signifikan & $\beta_{11}$ & $-5853,36$ & $7,72 \times 10^{-12}$ & Signifikan \\
$\beta_{4}$ & $-6605,11$ & $1,653 \times 10^{-14}$ & Signifikan & & & & \\
\hline
\end{tabular}

Tabel 3 menunjukkan semua parameter telah signifikan karena nilai-p kurang dari 0,05 , selanjutnya dilanjutkan uji white noise dan uji normalitas. Hasil uji white noise menunjukkan nilai-p untuk 12 lag pertama sebesar 0,5366 yang berarti tidak terdapat korelasi antar residu. Hasil uji normalitas menunjukkan nilai- $p$ sebesar 0,5771 yang berarti residu berdistribusi normal. Berdasarkan hal tersebut, model SARIMAX $(0,0,0)(1,0,1)^{12} \quad V_{t}, \quad S_{s, t} ; \quad s=2,3,4,5,6,7,9,10,11$ cocok untuk meramalkan banyak pengunjung pantai Pandansimo.

2) Model SARIMAX $(0,0,0)(0,0,1)^{12}$

Hasil estimasi parameter model SARIMAX $(0,0,0)(0,0,1)^{12}$ disajikan pada Tabel 4. Tabel 4 menunjukkan semua parameter telah signifikan karena nilai-p kurang dari 0,05 , selanjutnya dilanjutkan uji white noise dan uji normalitas. Hasil uji white noise menunjukkan nilai- $p$ untuk 12 lag pertama sebesar 0,4344 yang berarti tidak terdapat korelasi antar residu. Hasil uji normalitas menunjukkan nilai- $p$ sebesar 0,481 yang berarti residu berdistribusi normal. Berdasarkan hal tersebut, model SARIMAX $(0,0,0)(0,0,1)^{12}$ $V_{t}, S_{s, t} ; s=2,3,4,5,6,7,9,10,11$ cocok untuk meramalkan banyak pengunjung pantai Pandansimo.

Tabel 4. Hasil Estimasi Parameter Model SARIMAX $(0,0,0)(0,0,1)^{12}$

\begin{tabular}{|c|c|c|c|c|c|c|c|}
\hline $\begin{array}{l}\text { Para- } \\
\text { meter }\end{array}$ & Estimasi & Nilai- $p$ & Ket & $\begin{array}{l}\text { Para- } \\
\text { meter }\end{array}$ & $\begin{array}{l}\text { Esti- } \\
\text { masi } \\
\end{array}$ & Nilai- $p$ & Ket \\
\hline$\theta_{1}$ & $-0,99998$ & $1,09 \times 10^{-5}$ & Signifikan & $\beta_{5}$ & $\begin{array}{c}- \\
1863,96\end{array}$ & 0,00867 & Signifikan \\
\hline$\beta_{0}$ & 14298,36 & $<2,2 \times 10^{-16}$ & Signifikan & $\beta_{6}$ & $\begin{array}{c}- \\
5009,26\end{array}$ & $1,74 \times 10^{-12}$ & Signifikan \\
\hline$V_{t}$ & 16723,35 & $<2,2 \times 10^{-16}$ & Signifikan & $\beta_{7}$ & $\begin{array}{c}- \\
8582,17\end{array}$ & $<2,2 \times 10^{-16}$ & Signifikan \\
\hline$\beta_{2}$ & $-7740,08$ & $<2,2 \times 10^{-16}$ & Signifikan & $\beta_{9}$ & $\begin{array}{c}- \\
3287,33\end{array}$ & $3,68 \times 10^{-6}$ & Signifikan \\
\hline$\beta_{3}$ & $-5376,97$ & $3,71 \times 10^{-14}$ & Signifikan & $\beta_{10}$ & $\begin{array}{c}- \\
4776,26\end{array}$ & $1,75 \times 10^{-11}$ & Signifikan \\
\hline$\beta_{4}$ & $-6459,99$ & $<2,2 \times 10^{-16}$ & Signifikan & $\beta_{11}$ & $\begin{array}{c}- \\
5781,85 \\
\end{array}$ & $3,92 \times 10^{-16}$ & Signifikan \\
\hline
\end{tabular}


3) Model SARIMAX $(0,0,0)(1,0,0)^{12}$

5.

Hasil estimasi parameter model SARIMAX $(0,0,0)(1,0,0)^{12}$ disajikan pada Tabel Tabel 5 Hasil estimasi parameter model SARIMAX $(0,0,0)(1,0,0)^{12}$

\begin{tabular}{rccccccc}
\hline $\begin{array}{c}\text { Para- } \\
\text { meter }\end{array}$ & Estimasi & Nilai- $p$ & Ket & $\begin{array}{c}\text { Para- } \\
\text { meter }\end{array}$ & Estimasi & Nilai- $p$ & Ket \\
\hline$\phi_{1}$ & $-6,80 \times 10^{-2}$ & 0,00675 & Signifikan & $\beta_{4}$ & $-5,5710^{3}$ & 0,00039 & Signifikan \\
$\beta_{0}$ & $1,32 \times 10^{4}$ & $<2,2 \times 10^{-16}$ & Signifikan & $\beta_{6}$ & $-4,4510^{3}$ & 0,00497 & Signifikan \\
$V_{t}$ & $1,63 \times 10^{4}$ & $3,11 \times 10^{-16}$ & Signifikan & $\beta_{7}$ & $-6,8110^{3}$ & 0,00034 & Signifikan \\
$\beta_{2}$ & $-6,57 \times 10^{3}$ & $2,79 \times 10^{-5}$ & Signifikan & $\beta_{10}$ & $-3,6610^{3}$ & 0,01975 & Signifikan \\
$\beta_{3}$ & $-4,55 \times 10^{3}$ & 0,00379 & Signifikan & $\beta_{11}$ & $-4,7010^{3}$ & 0,00273 & Signifikan \\
\hline
\end{tabular}

Tabel 5 menunjukkan semua parameter telah signifikan karena nilai-p kurang dari 0,05 , selanjutnya dilanjutkan uji white noise dan uji normalitas. Hasil uji white noise menunjukkan nilai-p untuk 12 lag pertama sebesar 0,6997 yang berarti tidak terdapat korelasi antar residu. Hasil uji normalitas menunjukkan nilai- $p$ sebesar 0,8038 yang berarti residu berdistribusi normal. Berdasarkan hal tersebut, model SARIMAX $(0,0,0)(1,0,0)^{12} V_{t}, S_{s, t} ; s=2,3,4,6,7,10,11$ cocok untuk meramalkan banyak pengunjung pantai Pandansimo.

\subsection{Pemilihan Model Terbaik}

Hasil pemilihan model terbaik bedasarkan pada nilai RMSE out-sample terkecil. Perhitungan RMSE in-sample dan RMSE out-sample disajikan pada Tabel 6.

Tabel 6. Perbandingan RMSE in-sample dan RMSE out-sample

\begin{tabular}{lcc}
\hline \multicolumn{1}{c}{ Model } & $\begin{array}{c}\text { RMSE } \text { in- } \\
\text { sample }\end{array}$ & $\begin{array}{c}\text { RMSE } \text { out- } \\
\text { sample }\end{array}$ \\
\hline Model Regresi Runtun Waktu & 3366,39 & 4746,40 \\
Model SARIMAX $(0,0,0)(1,0,1)^{12} V_{t}, S_{s, t} ;$ & 2508,05 & 5190,04 \\
$s=2,3,4,5,6,7,9,10,11$ & 2507,17 & 5972,36 \\
$\begin{array}{l}\text { Model SARIMAX }(0,0,0)(0,0,1)^{12} V_{t}, S_{s, t} ; \\
s=2,3,4,5,6,7,9,10,11\end{array}$ & 3360,08 & 4826,32 \\
$\begin{array}{l}\text { Model SARIMAX }(0,0,0)(1,0,0)^{12} V_{t}, S_{s, t} ; \\
s=2,3,4,6,7,10,11\end{array}$ & & \\
\hline
\end{tabular}

Tabel 6 menunjukkan bahwa model regresi runtun waktu memiliki nilai RMSE out-sample terkecil yaitu 4746,40 sehingga model tersebut merupakan model terbaik. Selanjutnya model tersebut digunakan untuk meramalkan banyak pengunjung Pantai Pandansimo periode mendatang. Plot nilai data out-sample dan hasil peramalan dari 
model terbaik bulan Januari 2017 sampai dengan Desember 2017 disajikan pada Gambar 4.

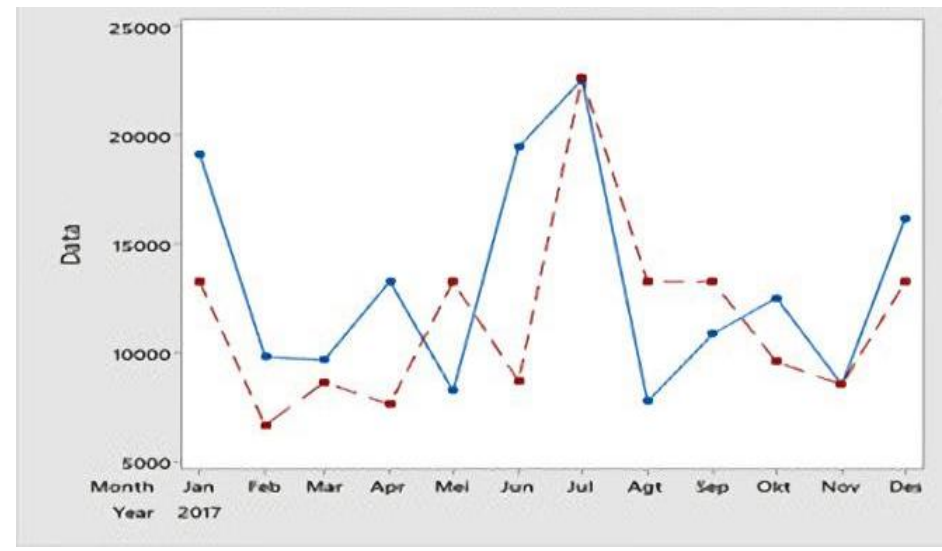

Gambar 4. Plot Nilai Data Asli (biru) dan Hasil Peramalan dari Model Terbaik (merah)

Gambar 4 menunjukkan bahwa hasil peramalan untuk bulan Januari, April, Mei, Juni, Agustus tidak mendekati nilai data asli, sedangkan hasil peramalan untuk bulan Februari, Maret, Juli, September, Oktober, November, Desember mendekati nilai data asli. Langkah selanjutnya adalah melakukan peramalan banyak pengunjung Pantai Pandansimo pada bulan Januari sampai bulan Desember 2018 menggunakan model terbaik. Hasil peramalan pada bulan Januari sampai bulan Desember 2018 secara berturut-turut adalah 13255, 6674, 8643, 7639, 13255, 8713, 22635, 13255, 13255, 9590, 8549,13255 pengunjung.

\section{Kesimpulan}

Model regresi runtun waktu untuk meramalkan banyak pengunjung pantai Pandansimo dinyatakan dengan persamaan

$$
\begin{aligned}
Z_{t}= & 13255+15978 V_{t}-6580 S_{2, t}-4613 S_{3, t}-5616 S_{4, t}-4542 S_{6, t}-6599 S_{7, t}-3665 S_{10, t}- \\
& 4706 S_{11, t}
\end{aligned}
$$

Model SARIMAX terbaik yang sesuai untuk peramalan data banyak pengunjung Pantai Pandansimo menggunakan model SARIMAX $(0,0,0)(1,0,0)^{12}$ dengan persamaan. Nilai peramalan banyak pengunjung Pantai Pandansimo bulan Januari sampai Desember 2018 menggunakan model yang lebih baik adalah 13255, 6674, 8643, 7639, 13255, 8713, $22635,13255,13255,9590,8549,13255$. 


\section{Daftar Pustaka}

[1] Hanke, J. and Wichern, D. Business Forecasting. Pearson Education International. New York. 2005.

[2] Lee, M.H., Suhartono, and Hamzah, N. A. Calender Variation Model Based on Time Series Regression for Sales Forecast The Ramadhan Effects, Proceedings of the Regional Conference on Statistical Sciences. 2010.

[3] Cosasi, A. Peramalan Jumlah Pengunjung Grojogan Sewu Menggunakan Model Regresi Runtun Waktu dengan Variasi Kalender. Skripsi S1 Program Studi Matematika FMIPA. Universitas Sebelas Maret. Surakarta. 2014.

[4] Sofyana,Y., Gumgum D. dan Resa S.P. Peramalan Jumlah Penumpang Kereta Api Fajar Utama Yogya Jurusan Yogyakarta-Pasar Senen menggunakan Variasi Kalender ARIMAX. Prosiding Seminar Nasional MIPA, Jatinangor, 27-28 Oktober 2016.

[5] Arunraj, N. S., Ahrens D., and Fernandes M. Application of SARIMAX Model to Forecast Daily Sales in Food Retail Industry. IJORIS. Vol 7(2), 1-21. 2016.

[6] Statistik Kepariwisataan. Dinas Pariwisata Provinsi Daerah Istimewa Yogyakarta. 2018. Diakses 8 Maret 2019, 16:48 WIB. https://visitingjogja.com 